\title{
Craquelure structure of protein film modification under the laser radiation of different spectral range action
}

\author{
Alexander N. Malov, Anna V. Neupokoeva , and Evgeniya M. Kudryashova \\ Department of Medical and Biological physics, Irkutsk State Medical University, 1 Krasnogo Vosstaniya Str., \\ Irkutsk 664009, Russia \\ *e-mail: annett 2005@inbox.ru
}

\begin{abstract}
A craquelure structure of protein film as indicator of macromolecule state is discussing. Craquelure is a network of fine cracks or crackles on the surface of a painting, caused chiefly by shrinkage of paint film or varnish. The actions of laser radiation in the red and green spectral region on the protein film craquelure structure by the example of albumin are considering. It is experimentally shown that after drying the protein layer a craquelure pattern (variety of cracks in the layer) is formed with the parameters strongly modified by the laser action and depending on the wavelength of radiation and the time (energy density) of exposure. (C) 2016 Journal of Biomedical Photonics \& Engineering.
\end{abstract}

Keywords: craquelure, crack, albumin, film, image processing, structure monitoring, laser biostimulation.

Paper \#2989 received 2016.02.29 revised manuscript received 2016.03.23; accepted for publication 2016.03.23; published online 2016.03.31. doi: 10.18287/JBPE16.02.010307

\section{References}

1. N. Y. Ilyasova, A. V. Kupriyanov, and A. G. Khramov, Information technologies of image analysis in the problems of medical diagnostics, A. S. Bugayev (ed.), Radio i svyaz, Moscow (2012) [in Russian].

2. E. G. Rapis, "Self-assembly of cluster protein films (allotropic nonequilibrium noncrystalline modification) during the process or their condensation," Technical Physics 45(1), 121-131 (2000).

3. E. Rapi, "Properties and symmetry of the solid cluster phase of protein," Technical Physics 46(10), 1307-1313 (2001).

4. E. Rapis, "A change in the physical state of a nonequilibrium blood plasma protein film in patients with carcinoma," Technical Physics 47(4), 510-512 (2002).

5. Y. Y. Tarasevich, "The models and mechanisms of the dehydration self-organization of biological fluids," Physics-Uspekhi 47(7), 717-728 (2004).

6. A. N. Malov, E. S. Musatova, A. U. Setejkin, and S. V. Zinoviev, "Laser nanoclasterization processes simulation," Modern Problems of Nanopharmacology, The $8^{\text {th }}$ Russia and China Pharmaceutical Forum, 14- 17 September 2011, Blagoveshchensk, 66 - 67 (2011).

7. A. N. Malov, E. S. Musatova, and A. Y. Seteikin, "Crystallographic recording of the results of laser-induced nanoclusterization of bioorganic fluids," V-th Troitsk Conference "Medical Physics and Innovations in Medicine", Book of Proceedings, vol. 2, OOO "TROVANT", Troitsk, Moscow Region, 80 - 82 (2012) [in Russian].

8. A. N. Malov, E. S. Musatova, and A. Y. Seteikin, "Study of specific features of nucleation in the planar crystallisation of bioorganic solutions on a solid substrate," Vestnik Amurskogo gosudarstvennogo universiteta 57, 39 - 44 (2012) [in Russian].

9. A. N. Malov, A. Y. Seteikin, A. V. Neupokoeva, E. S. Musatova, I. E. Golub, L. V. Sorokina, V. S. Fetschenko, and A. A. Vaichas, "The laser radiation action on the biological objects," Optik 124, 6034-6041 (2013).

10. S. Bucklow, "The Description and Classification of Craquelure," Studies in Conservation 44(4), 233-244 (1999).

11. W. V. Moreau, Microdevices. Physics and Fabrication Technologies, Plenum Press, New York (1988). 


\section{Introduction}

One of the main paradigms of medicine is that the pathologic organism status is reflected in the fluids that wash the cells of the body [1]. That is why in any patient the general analysis of blood and urine is performed first. However, solely the chemical analysis does not provide sufficient information, since it is unable to reveal the conformation modifications of the biological protein macromolecules. Besides, the conformation modifications of the protein molecules can manifest themselves before the chemical changes of the blood (urine) composition, or the clinical symptoms of the disease. Therefore, the early diagnostics is often possible using crystallograms.

In recent time the methods of analysing the crystallograms of biological fluids, produced by dehydration self-organisation of the protein solutions and other substances in the process of drying the solution on a solid substrate are in progress [1-5]. It is found that the patterns that appear in this case correlate well with the patient's health [1, 4]. It was also found that the method of film crystallograms is capable of detecting the result of the laser radiation action on a biological fluid [6-9], namely, the size reduction of the structure elements consisting of macromolecules is recorded (the phenomenon of laser-induced nanoclusterization).

The known studies in this field, as a rule, considered the dehydration of the fluid droplets on the substrate, when the formation of the crystal structure can be affected by both the change of the droplet area and the change of the wetting contact angle [5]. The difficulties can be avoided using the planar layers of protein, when the geometry of the films minimally changes in the drying process. By the end of drying the protein layer becomes covered with cracks forming a specific pattern referred to as craquelure pattern. The craquelure pattern (in French called craquelure) is formed by cracks of paint or varnish layer covering an oil-painted picture, which is known in art for a long time [10]. The cracks, i.e., the integrity defects of the layer of paint, varnish, or ground of a picture, possess various characters and pattern and directly depend upon the fluid composition and the cause of their origin. The craquelure effect also is used in manicure technologies.

In the present paper we consider the laser radiation action on the craquelure pattern of a protein film by the example of albumin. Possible applications of this effect may be related both to the control of the forming patterns aimed at the facilitation of decoding the resulting craquelure patterns and to the determination of the energy doses when exposing, e.g., medication solutions with the aim to activate them (similar to the analgesic activation under the intravenous irradiation of blood [9], which, in turn, allows the reduction of the narcosis amount).

\section{Crack formation in polymer layers}

In the process of dehydration (drying) of a biological fluid in the form of a film poured onto a solid (usually glass) substrate a number of processes simultaneously occur. They are the evaporation of the solvent (water), the diffusion of the solution components over the film, the sedimentation of molecules and their associates onto the substrate, the modification of molecular conformations, and the swelling-induced variation of the film thickness $[1,5,10,11]$. As a whole, the drying film can be considered as possessing a layered structure; the most massive macromolecules and their associates are the first to be attached to the substrate as having the minimal velocity of thermal motion. Then they play the role of nucleation centres in the formation of the crystallographic pattern. From the surrounding solution the growth of crystallites consisting of lighter molecules occurs reducing the concentration of the admixtures in the solvent, which in turn affects the evaporation rate. As a result the formation of puncture-type defects can happen due to different reasons, including the excretion of dissolved gases [11].

The effect of "cracking" is based on the difference in the drying time between the underlying layer and the coating (liquid and gel-like surface layer) which is cracked. Some craquelure compositions become fully dried in several days. Such underdried composition strongly extracts water from the water-based paint or varnish material and provides a sufficiently "slippery" surface for the paint or varnish that cracks in the course of drying on it $[5,10]$. The cracks can vary from the extremely fine hairline to considerable ones. The cracks, i.e., the defects of the pain, varnish, or ground layer integrity, possess different character and form different patterns directly reflecting their cause. A known from photography, besides the crack formation, the shrinkage of the surface layer (reticulation) can also occur. The action of laser radiation reduces the cluster size in a biological liquid [6- 8], which facilitates the formation of cracks, too.

\section{Materials and Methods}

As a model medium we used the egg protein albumin. The albumins are proteins of animal and plant tissues. They are globular proteins contained in the blood plasma and egg white, executing the transport and nutrition functions, respectively. Their content approaches $50 \%$ of the total amount of protein in the tissue. We suggest that under the action of laser radiation on blood the structure of blood proteins is changed, which is an important link in the development of the biological response to the laser impact. Therefore, if our experiments with albumin will demonstrate the change of its structure and we will be able to visualise these changes, then it will be possible to expect similar changes in the blood proteins.

As sources of laser radiation we used the semiconductor laser units with the wavelengths $530 \mathrm{~nm}$ and $650 \mathrm{~nm}$. 
After separating the egg white from yolk the white was divided into three portions. Then two portions were sequentially irradiated, the first one with the radiation having the wavelength $530 \mathrm{~nm}$ and the power about 80 $\mathrm{mW}$ (nearly $1200 \mathrm{~mW} / \mathrm{cm}^{2}$ ) during 2 minutes, and the second one with the radiation having the wavelength $650 \mathrm{~nm}$ and the power about $10 \mathrm{~mW}$ (nearly 150 $\mathrm{mW} / \mathrm{cm}^{2}$ ) during 20 minutes. Therefore, the total energy of irradiation amounted to $10 \mathrm{~J}$ (the energy density being nearly $150--180 \mathrm{~J} / \mathrm{cm}^{2}$ ) for each of the irradiated samples. Then all samples were poured onto glass plates and kept at room temperature until dried. After drying the protein layer acquired cracks forming the characteristic craquelure pattern.

\section{Results and Discussion}

The effect of laser exposure on albumin was assessed by observing the craquelure patterns on the dried film (Fig. 1). The patterns were observed visually and using a web camera. By the naked eye it was seen that the nonexposed samples had thick and larger cracks, while the air bubbles were present in small amount. The protein structure after the laser impact is finer, the bubbles and cracks are closer to each other and smaller in size. After the irradiation with red light the number of bubbles is significantly larger, while after the irradiation with green light only the reduction of the crack size and bubble diameter occurs, their number being comparable with than in the control unexposed sample.

Using the photographs from the web camera it was calculated that the mean diameter of a bubble in the control unexposed samples was 5--6 $\mathrm{mm}$ and in the exposed ones 2--3 $\mathrm{mm}$.

We also sought the threshold energy, i.e., the minimal energy of the laser radiation, causing the observable changes in the craquelure pattern. Figures. 2, 3 present the results of irradiating albumin with laser light with the wavelength $650 \mathrm{~nm}$ during different time. From the comparison of patterns obtained after different times of exposure one can see that in the control sample, after 1 and 2 minutes of exposure the patterns are similar, and the characteris-tic pattern size visible in the microscope amounts to nearly $70 \mu \mathrm{m}$. For the exposure time of 5 minutes it is visually seen that the structures of the pattern becomes finer. The calculations show that its diameter amounts to nearly $40 \mu \mathrm{m}$. For the exposure time greater than 5 minutes the structure becomes more inhomogeneous due to the appearance of small-scale elements with the size of about $20 \mu \mathrm{m}$.

From the presented data it follows that the changes in the pattern become observable after the exposures from 5 minutes and longer, which corresponds to the total energy of impact about $3 \mathrm{~J}$ (or the energy density about $50 \mathrm{~J} / \mathrm{cm}^{2}$ ).

Figure 3 presents the photographs of the patterns on the albumin layer from the same series, as shown in Fig. 2. However, for clarity only the samples separated by the expose time difference of 10 minutes are left, which allows to trace the modifications by the naked eye. Thus, for the exposure time of 10 minutes the bubble size seems to decrease as compared to the control sample and continues to decrease with the increasing exposure time.

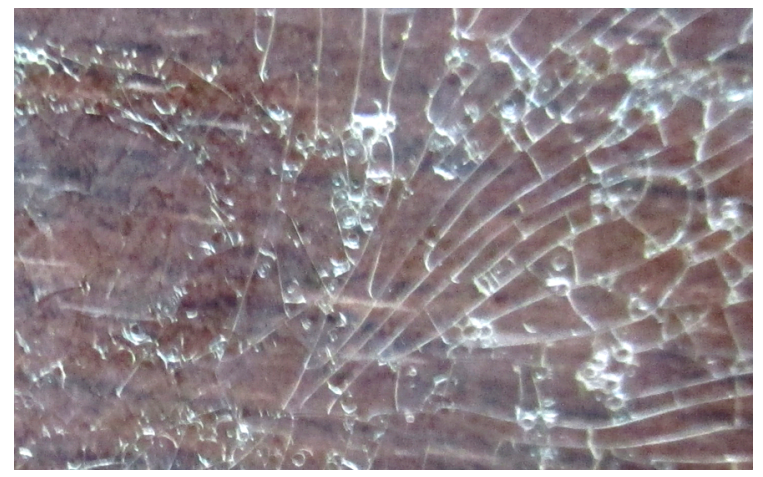

Without laser impact

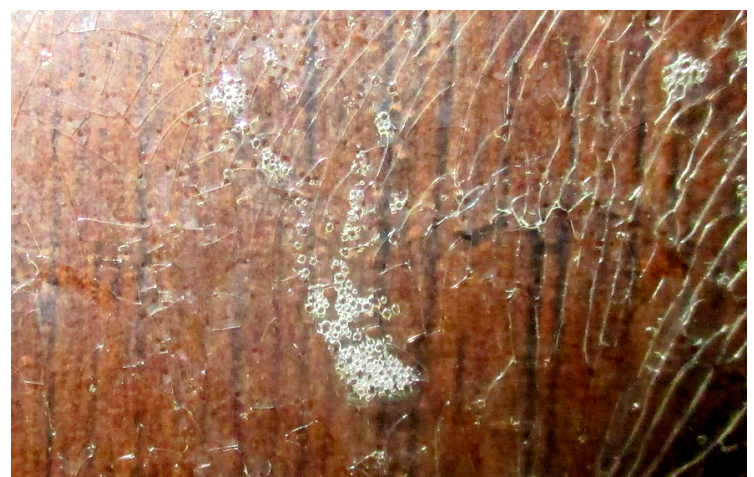

After the impact of laser radiation with the wavelength $530 \mathrm{~nm}$

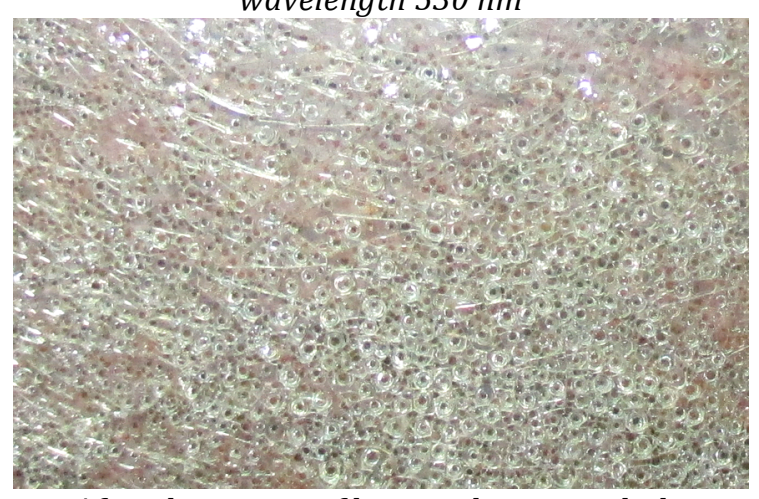

After the impact of laser radiation with the wavelength $650 \mathrm{~nm}$

Fig. 1 Typical craquelure patterns in the dry layers of albumin.

\section{Conclusion}

Thus, it is shown that the parameters of craquelure structure (the size of bubbles and cracks and the separations between them) are essentially reduced after the laser impact on the protein. Besides, it was found that the laser radiation with the wavelength $650 \mathrm{~nm}$ exerts more expressed influence on the shelling pattern of the albumin layer, and the threshold energy density is nearly $50 \mathrm{~J} / \mathrm{cm}^{2}$. 


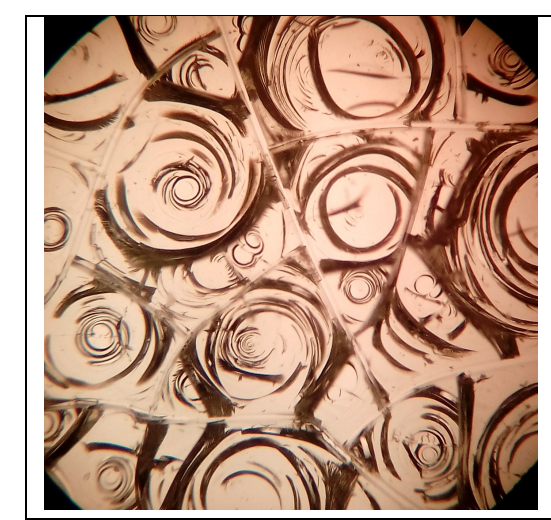

0 minutes;

Characteristic diameter of the

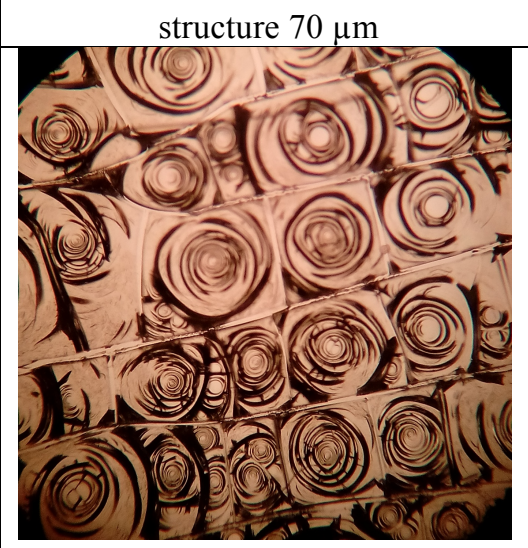

5 minutes $\left(45 \mathrm{~J} / \mathrm{cm}^{2}\right)$;

Characteristic diameter of the structure $40 \mu \mathrm{m}$

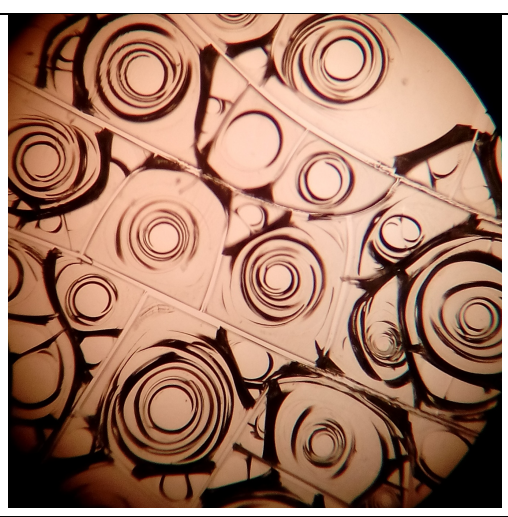

1 minute $\left(9 \mathrm{~J} / \mathrm{cm}^{2}\right)$;

Characteristic diameter of the structure $70 \mu \mathrm{m}$

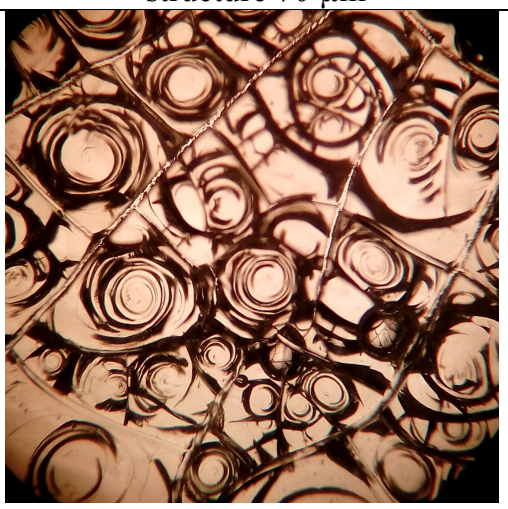

10 minutes $\left(90 \mathrm{~J} / \mathrm{cm}^{2}\right)$;

Characteristic diameter of the structure $40 \mu \mathrm{m}$, but the structures of nearly $20 \mu \mathrm{m}$ appear

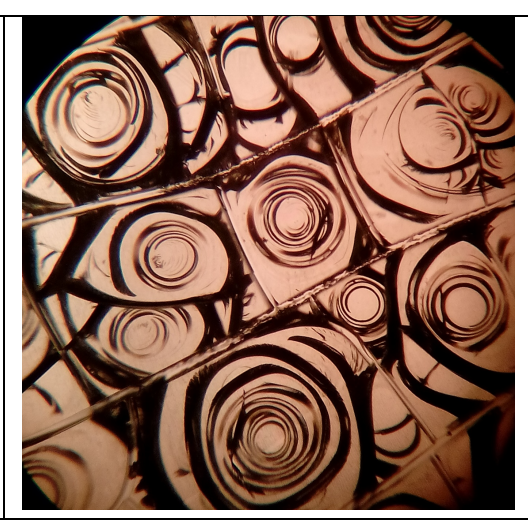

2 minutes $\left(18 \mathrm{~J} / \mathrm{cm}^{2}\right)$;

Characteristic diameter of the

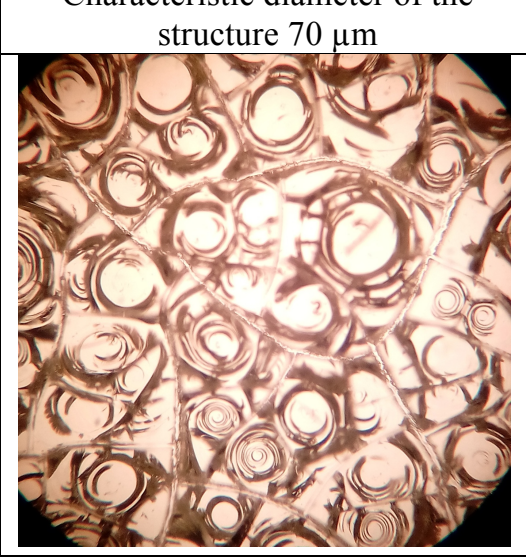

20 minutes $\left(180 \mathrm{~J} / \mathrm{cm}^{2}\right)$;

Characteristic diameter of the structure 20-30 $\mu \mathrm{m}$

Fig. 2 Typical microscopic view of craquelure patterns in dry layers of albumin after different times of exposure to laser radiation with the wavelength $\lambda=650 \mathrm{~nm}$.

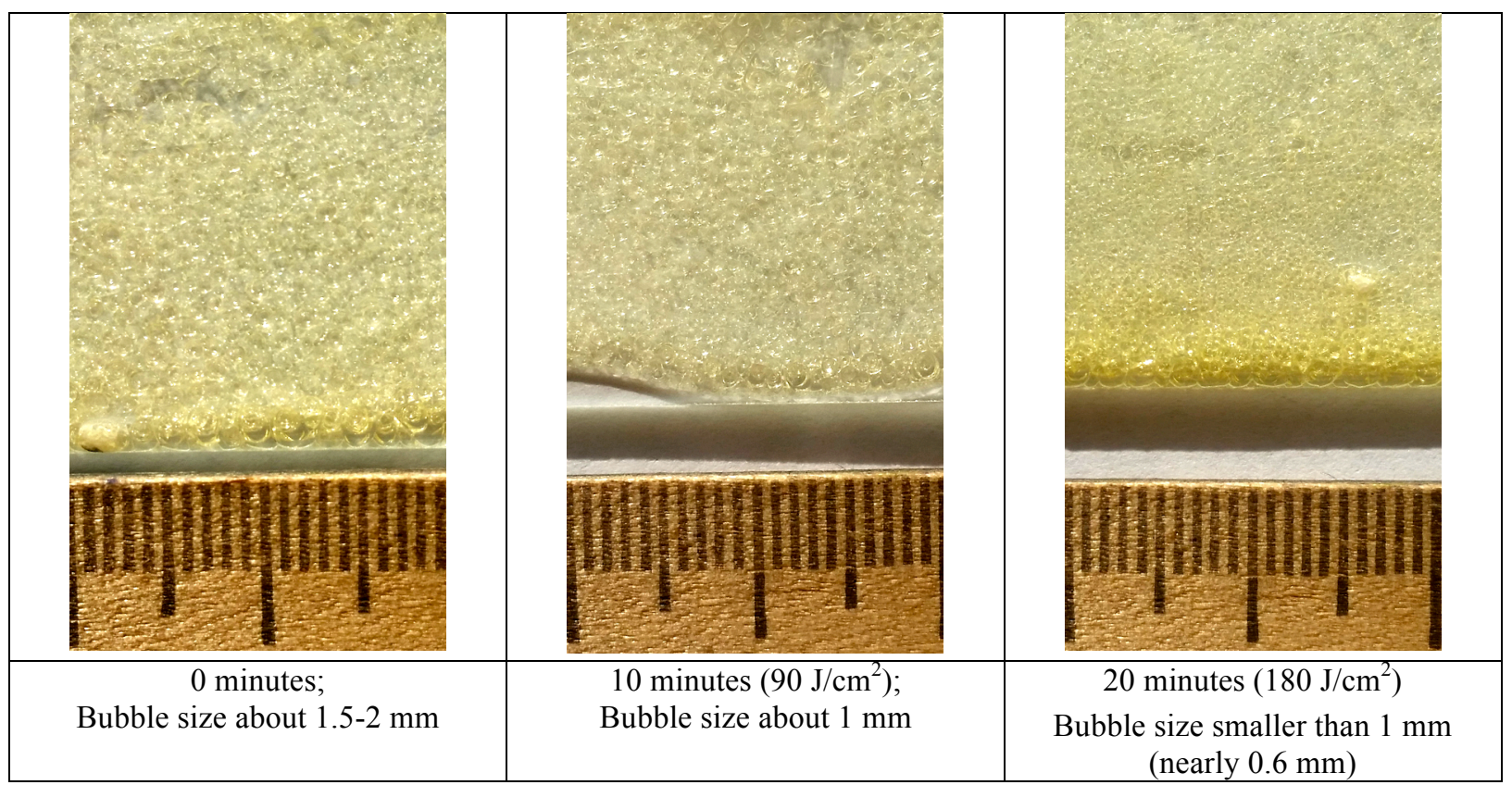

Fig. 3 Typical view of craquelure patterns in dry layers of albumin after different times of exposure to laser radiation with $\lambda=650 \mathrm{~nm}$. 